\title{
Using Professional Development Opportunities to Advance Your Nuclear Medicine Career
}

\author{
Jared D. Seliger, CNMT, PET, RT(N)
}

Allen College, Waterloo, Iowa

\begin{abstract}
Nuclear medicine technologists (NMTs) have multiple opportunities to advance their careers beyond an entry-level NMT. Many careers that NMTs can obtain require additional skills, education, or qualifications. Participating in professional development (PD) opportunities is necessary to acquire the skills necessary for career advancement. PD opportunities can come from professional societies or organizations, be sponsored by an institution or employer, or come from participating in an educational degree program or advanced certificate program. The type or types of PD in which NMTs should engage will be unique for the type of position they are striving for and their current skills, knowledge, and educational level. The advantages and disadvantages of each type of PD should be considered by NMTs who are wishing to advance their careers and to select the development path that is most suited for their needs.
\end{abstract}

Key Words: professional development; continuing education; career advancement

J Nucl Med Technol 2019; 47:130-132

DOI: 10.2967/jnmt.118.210351

$\mathbf{O}$ ne aspect of the nuclear medicine profession that should be leveraged to attract more individuals to the field is the vast number of career opportunities a nuclear medicine technologist (NMT) can pursue. People who graduate from an entry-level nuclear medicine technology educational program have the ability to develop their career from the foundation of being a staff NMT. These opportunities include, but are not limited to, department manager or supervisor, radiology manager, hospital administrator, NMT education faculty, NMT program director, equipment salesperson, and vendor applications specialist.

Many of these careers require NMTs to advance their education level, knowledge, or skill set beyond what is provided in an entry-level NMT education. For example, the July 2018 Accreditation Standards for Nuclear Medicine Technologist Education of the Joint Review Committee for Education Programs in Nuclear Medicine Technology states

Received Sep. 4, 2018; revision accepted Dec. 3, 2018.

For correspondence or reprints contact: Jared D. Seliger, Allen College, 1825 Logan Ave., Waterloo, IA 50703.

E-mail: jared.seliger@allencollege.edu

Published online Jan. 29, 2019.

COPYRIGHT (c) 2019 by the Society of Nuclear Medicine and Molecular Imaging. that the minimum requirements to be an NMT program director include holding a master's degree from a regionally or nationally accredited college or university, having $4 \mathrm{y}$ of experience as a certified NMT, and having at least $1 \mathrm{y}$ of teaching experience (either didactic or clinical) (1). To achieve these minimum standards, an NMT must engage in one or more forms of professional development (PD).

PD is the advancement of expertise or skills in a particular profession through a continuing education program (2). PD activities can be obtained through the following sources: professional organizations (including journals or conferences related to the professional organization), institution-sponsored programs, and a formal educational program (3). The type of PD in which NMTs engage needs to be individually tailored to their career aspirations and current skill and knowledge level. Each type of PD and its advantages and disadvantages are summarized in Table 1.

\section{PROFESSIONAL ORGANIZATIONS}

Most health-care professions have their own national (or international) professional organizations (4). The main benefit of using professional organizations for PD is that they convey specific information related to the profession. NMTs rely on the Society of Nuclear Medicine and Molecular Imaging (SNMMI) as a primary source of news, information, and development opportunities. The pinnacle of most professional organizations is a national annual meeting where experts across the field convene to discuss the current trends and future innovations of the profession (5). In addition to the annual meeting, most professional organizations have monthly publications that contain peer-reviewed articles about topics related to the profession. Websites, listserves, and newsletters are other methods professionals can use to collaborate with experts in the field (4).

The SNMMI provides specific PD offerings for NMTs to help advance their career. The SNMMI hosts an annual national meeting that allows NMTs to participate in PD and continuing education and to connect with peers and mentors. The SNMMI also offers a Leadership Academy to provide specific leadership development to NMTs who have high leadership potential. Additionally, several online resources such as journals, teaching cases, and certification examination study guides are provided, all with the intention of helping advance the NMT's career. 


\begin{tabular}{lll}
\hline \multicolumn{1}{c}{ Type } & \multicolumn{1}{c}{ Advantage } & \multicolumn{1}{c}{ Disadvantage } \\
\hline Professional organizations & Closely related to profession & Costly, travel to annual meeting \\
Institution-sponsored & Most cost-efficient, local & Very broad topics \\
Courses or seminars & Pathway to a degree or credential & Very costly and time-consuming \\
\hline
\end{tabular}

Professional organizations are typically the first choice for people who wish to receive PD that is specific to their profession. The main advantage of participating in PD from a professional organization is that the organization can identify trends within the profession more quickly than any other method (5). Professional organizations also are a source of access to peers who have progressed their careers and can serve as mentors.

Using professional societies for PD does have a few disadvantages. First, membership in a professional society can be costly, and depending on employer policy, the cost may be the responsibility of the individual (3). If cost is a factor, the individual might not be able to take advantage of all the services a professional society has to offer. Another potential issue is the location of the annual national meeting. Some career and technical education instructors may not be able to travel to the meeting on a consistent basis because of distance or cost considerations.

\section{INSTITUTION-SPONSORED}

Institution-sponsored PD consists of activities that are organized and occur within the walls of the hospital or place of employment. In most cases, institutional PD is organized and monitored by an internal member of the organization or a department (6). The PD committee or department typically has a budget approved by the administration of the organization, with the size of the budget varying greatly among various institutions.

The PD occurring at the institutional level typically relates to skills required for success in a particular employment setting. The PD committee requests feedback or input from team members on desired content areas and then develop activities to meet the needs of the team (6). In most cases, institutional PD is often led by an internal member of the organization with expertise on a specific topic (e.g., leadership development).

NMTs working at a hospital or radiology clinic may have an opportunity to cross-train in other departments, such as $\mathrm{CT}$ or MRI. Cross-training is a form of on-the-job training and can provide a pathway to eligibility for certification through the American Registry of Radiologic Technologists in CT or MRI.

The main benefit of institutional PD is that it is usually the least costly of any PD activity described in this article. The activities are held in a classroom or conference room at the institution, and there is no need to pay for travel. Sometimes, institutions incur costs to bring an outside speaker into the facility, but those costs are significantly less than to send large numbers of employees to outside meetings or conferences (3).

Like professional society PD, institutional PD does have disadvantages. PD related to technical skills (e.g., something specific for NMTs) usually does not occur at the institutional level because technical skills vary by profession. Another disadvantage is that this approach is broad and might not be relevant to all employees of the institution.

\section{COURSES AND SEMINARS}

Courses and seminars are the final type of PD that this article will explore. Enrolling in college courses is another way for individuals to obtain PD for career advancement. The courses can be either individual courses related to a specific topic or part of a plan of study toward an advanced degree (5). The main difference between enrolling in a course versus a seminar is that a course usually is for college credit and a seminar is not. Any courses or seminars in which NMTs enroll need to fill the gap in knowledge, credentials, or degree level preventing advancement to their desired career. For example, if the goal is to become an NMT program director, and the highest level of education that has been obtained by the individual is a bachelor's degree, that person would need to enroll in an academic program of study that concludes with the conferral of a master's degree.

The method of delivering the courses and seminars has evolved over the last several decades. Traditionally, courses and seminars were held in classrooms or dedicated conference locations. The date and location of courses and seminars may have been a barrier for participation because of work and family commitments. Today, academic courses, degree programs, and seminars may be attended virtually through hybrid or entirely online formats. Many colleges and universities have online course and degree options that are tailored to working professionals through asynchronous course attendance. Professional societies such as the SNMMI provide online seminars, audio lectures, and PD.

Like the previously mentioned activities, enrolling in courses and seminars does have its disadvantages. Taking a single course or enrolling in an advanced-degree program can be extremely time-consuming. It can be difficult for NMTs who have full-time employment to manage their career as well as the responsibilities of being a student (7). If the NMT's work schedule conflicts with the time a course is offered, it may be difficult to complete the educational program. Finally, tuition can be a major barrier to pursuing courses or seminars. Some employers have tuition reimbursement 
policies that cover part or all of the cost associated with course enrollment if it directly improves the employee's skill set or addresses a specified need within the organization (5). However, because of the current financial hardships of many health-care organizations, tuition reimbursement may have been dramatically reduced or cut altogether, resulting in the individual's being responsible for covering the costs.

\section{CONCLUSION}

When NMTs are evaluating career progression opportunities, the most basic consideration is what skills, degrees, or credentials are needed. It is likely that career advancement will require participating in most or all of the types of PD identified in this article. Although the path is going to be unique for every NMT who wishes to advance to the next career stage, here are some recommendations for obtaining the necessary PD.

Professional organizations such as the SNMMI are a great resource for PD and include a community of members who are at various career stages. With your career path in mind, find someone within the SNMMI who has a role similar to what you are trying to obtain and ask that person to be your mentor and guide your career development. Mentors can be extremely beneficial by sharing how they advanced their career and describing the types of PD that were most valuable to them.

Educational-degree or advanced-certificate programs are the PD opportunities that take the most time to complete. A recommendation would be to begin your PD by enrolling in an educational program that leads to an advanced degree. Most NMT career paths, such as education or hospital administration, either require or highly recommend a master's-level (or higher) degree. Even if the career you are seeking does not require an advanced degree, having obtained the degree can differentiate you from other individuals striving for that career.
Finally, it is recommended that you take advantage of any PD that your employer offers. Most medium or large health-care organizations have an organizational development department that conducts PD activities for employees. Participating in institution-sponsored PD creates visibility for you within the organization and is a clear indication that you intend to advance your career.

The career possibilities for NMTs are numerous, and participating in the various forms of PD can provide the skills and expertise necessary to qualify for those careers. If you wish to advance your career, developing a personal PD path can lead to the career you desire.

\section{DISCLOSURE}

No potential conflict of interest relevant to this article was reported.

\section{REFERENCES}

1. Accreditation Standards for Nuclear Medicine Technologist Education. JRCNMT website. https://www.jrcnmt.org/sites/jrcnmt2/uploads/documents/Accred_Policy_ Documents/Standards_June2018rev.pdf. Published July 1, 2018. Accessed February $11,2019$.

2. Wonacott ME. Teacher Induction Programs for Beginning CTE Teachers. Columbus, $\mathrm{OH}$ : National Dissemination Center for Career and Technical Education in Brief; 2002.

3. Smith CL, Edmunds NA. Career and Technical Educator's Survival Guide. Alexandria, VA: Association for Career and Technical Education; 1999

4. Orr MT. Career academies as a professionally engaging and supportive teaching experience. Educ Urban Soc. 2005;37:453-489.

5. Wichowski CP, Heberly G. A Summary Report on Priorities in CTE Professional Development. Alexandria, VA: Association for Career and Technical Education; 2004.

6. Mukherjee H, Singh JS. Staff Development Approaches in Higher Education: Learning from Experience. London, U.K.: Commonwealth Secretariat; 1993.

7. Stipanovic N, Lewis MV, Stringfield S. Situating programs of study within current and historical career and technical educational reform efforts. Int J Educ Reform. 2012;21:80-97. 